\title{
Cdx2 Protein Expression in Normal and Malignant Human Tissues: An Immunohistochemical Survey Using Tissue Microarrays
}

Christopher A. Moskaluk, M.D., Ph.D., Hong Zhang, M.D., Steven M. Powell, M.D., Lisa A. Cerilli, M.D., Garret M. Hampton, Ph.D., Henry F. Frierson, Jr., M.D.

Departments of Pathology (CAM, LAC, HFF), of Biochemistry and Molecular Genetics (CAM), and of Medicine (SMP), University of Virginia Health System, Charlottesville, Virginia; Department of Pathology (HZ), Anhui Medical University, Hefei, China; and Genomics Institute of the Novartis Research

Foundation (GMH), San Diego, California

Cdx2 has been identified as a marker of colon cancer in RNA-profiling experiments. We show here that the detection of $\mathrm{Cdx} 2$ protein by immunohistochemistry correlates well with RNA transcript levels as detected by oligonucleotide microarrays. Using tissue microarrays containing most normal tissue types and an antibody to the $\mathrm{Cdx} 2$ protein, strong diffuse Cdx2 staining was only seen in the nuclei of small and large intestinal epithelium and portions of the pancreatic duct system. In tissue microarrays containing 745 cancers from many anatomic sites, colonic adenocarcinomas showed strong extensive staining in $\mathbf{9 0 \%}$ of cases, with adenocarcinomas of the stomach, esophagus, and ovary (endometrioid and mucinous types) showing extensive staining in only $20-30 \%$ of cases. Other types of carcinomas showed extensive staining in only $\leq 1 \%$ of cases. Of 30 neuroendocrine tumors examined, carcinoids of the midgut and hindgut had the most cases with extensive staining $(73 \%$ and $44 \%$, respectively), thus paralleling the distribution of Cdx2 expression in adenocarcinomas. Cdx2 shows a limited range of expression in the spectrum of human tissues and neoplasia and thus may have utility in determining the site of origin of tumors in certain clinical situations.

\footnotetext{
Copyright () 2003 by The United States and Canadian Academy of Pathology, Inc.

VOL. 16, NO. 9, P. 913, 2003 Printed in the U.S.A.

Date of acceptance: May 29, 2003.

Hong Zhang is an ITREID fellow in the Center for Global Health at The University of Virginia and is supported by NIH Fogerty Grant D43TW00909-05.

Address reprint requests to: Christopher A. Moskaluk, M.D., Ph.D., Department of Pathology, University of Virginia Health System, Rm. 3890 Old Medical School Bldg., Jefferson Park Ave., Charlottesville, VA 22908; fax: 434-243-6757; e-mail: cam5p@virginia.edu.

DOI: 10.1097/01.MP.0000086073.92773.55
}

KEY WORDS: Cdx2, immunohistochemistry, RNA profiling, Tissue microarray.

Mod Pathol 2003;16(9):913-919

$C d x 2$ is a homeobox gene that has been shown to play a role in the development of the small and large intestine in mammals and in the differentiation of intestinal epithelial cells. The $C d x 2$ gene is expressed in all but the most distal portions of the intestinal tract during development $(1,2)$. In a cell culture model, Cdx2 has been shown to decrease cellular replication and induce differentiation to mature intestinal epithelium (3). Cdx2 acts as a transcription factor, increasing the expression of several gene products associated with mature intestinal epithelial cells $(3,4)$. Perhaps not surprisingly, $C d x 2$ has recently been identified as a gene whose expression had a high predictive value for the diagnosis of colonic adenocarcinoma in microarray gene expression analyses $(5,6)$. The use of Cdx2 as an immunohistochemical marker has been described recently in studies of human gastric and colon cancer, but no comprehensive survey of Cdx2 protein expression has been reported (7-9). To follow up on previous RNA transcript profiling data, we report our findings using immunohistochemistry on tissue microarrays to comprehensively profile the protein expression of $\mathrm{Cdx} 2$ in a broad range of human carcinomas and normal tissues.

\section{MATERIALS AND METHODS}

\section{Tissue Specimens}

Formalin-fixed, paraffin-embedded tissue blocks were obtained from the archives of the Department of Pathology of the University of Virginia Health System with institutional review board approval. 


\section{Tissue Microarrays}

Targeted tissue areas were marked on H\&Estained sections corresponding to the paraffin blocks. One to three $0.6-\mathrm{mm}$ tissue cores from each case were removed using a manual microarray device (Beecher Instruments, Silver Spring, MD) and inserted into recipient paraffin blocks. The tissue microarrays were sectioned at a $4-\mu \mathrm{m}$ thickness and placed on charged slides.

\section{Immunohistochemistry}

Tissue microarray and standard tissue histologic sections were deparaffinized, rehydrated, and blocked with methanolic 3\% hydrogen peroxide. The slides were immersed in $10 \mathrm{~mm}$ citrate buffer, pH 6.0 and heated in a 1200W microwave oven at the highest power setting. Evaporated liquid was replenished at 5 minutes, then the slides were heated at high power for an additional 5 minutes. The slides were left in the buffer for an additional 10 minutes before being removed. The antibody used was a mouse monoclonal antibody raised against full-length recombinant Cdx2 protein (AM392-5 M; BioGenex, San Ramon, CA). Immunostaining was performed by hand using the prediluted antibody solution and a 30-minute incubation. After washing, antibody binding was visualized using the avidin-biotin-peroxidase technique (Vectastain Elite ABC kit, Vector Laboratories, Burlington, VT), followed by incubation with 3,3'-diaminobenzidine tetrahydrochloride. The slides were counterstained with hematoxylin.

The immunohistochemical stains were evaluated by two pathologists (HFF and CAM). Only nuclear staining was considered positive, and it was scored on the following basis: 0 (no detectable staining $) ; 1+(<25 \%$ positive cells $) ; 2+(25-$ $49 \%) ; 3+(50-74 \%) ; 4+(>75 \%)$. In general, cases showing $3+$ and $4+$ staining also had strong intense staining, so intensity was not factored into the scoring.

The list of normal tissues examined is given in Table 1. Focal heterogeneous Cdx2 expression was present in the pancreatic tissue microarray samples, and standard histologic sections of this organ were also examined for confirmation of this finding.

The list of tumors examined is given in Table 2 . The following tumors were absent from or not well represented in the arrays, and additional cases were obtained and examined as standard histologic sections: germ cell tumors (12 additional cases), ampullary carcinoma (6 cases), and neuroendocrine carcinomas of the gastrointestinal tract, biliary tract, lung, and pancreas (30 cases).
TABLE 1. Cdx2 Immunohistochemical Staining in Normal Tissues

\begin{tabular}{|c|c|}
\hline No staining & Peripheral nerve \\
\hline Adipocytes & Pituitary \\
\hline Adrenal cortex & Placental membranes \\
\hline Adrenal medulla & Placental villi \\
\hline Anal squamous epithelium & Prostate \\
\hline Astroglia & Salivary gland, minor \\
\hline Bartholin gland & Salivary gland, parotid \\
\hline Bile duct epithelium & Salivary gland, submandibular \\
\hline Bladder transitional epithelium & Seminal vesicle \\
\hline Blood vessels & Skeletal muscle \\
\hline Bone & Skin, squamous epithelium \\
\hline Bone marrow & Skin, sweat glands \\
\hline Breast (duct epithelium) & Smooth muscle, uterus \\
\hline Breast (lobular epithelium) & Spinal cord \\
\hline Bronchial epithelium & Spleen \\
\hline Brunner glands & Stomach, antrum \\
\hline Cartilage (bronchus) & Stomach, fundus \\
\hline Endocervical epithelium & Synovium \\
\hline $\begin{array}{l}\text { Endometrial epithelium, } \\
\text { proliferative }\end{array}$ & Tendon \\
\hline Endometrial epithelium, secretory & Testis, Leydig cells \\
\hline Endometrial stroma & Testis, rete \\
\hline Endometrial stroma, decidualized & Testis, seminiferous tubules \\
\hline Epidiymis & Thymus \\
\hline Esophagus, squamous epithelium & Thyroid \\
\hline Esophagus, submucosal glands & Tonsil \\
\hline Fallopian tube & Ureter \\
\hline Gallbladder & Urethra, male \\
\hline Ganglia, peripheral & Vagina, squamous epithelium \\
\hline Heart, myocardium & Vas deferens \\
\hline Kidney, cortex & Vulva, squamous epithelium \\
\hline Kidney, medulla & Umbilical cord \\
\hline \multicolumn{2}{|l|}{ Lacrimal gland } \\
\hline Liver, hepatocytes & $2+$ staining \\
\hline Liver, portal tracts & $\begin{array}{l}\text { Pancreatic ducts, intermediate } \\
\text { to large cts }\end{array}$ \\
\hline \multicolumn{2}{|l|}{ Lung alveoli } \\
\hline Lymph node & $4+$ staining \\
\hline Lymphatics & Appendiceal epithelium \\
\hline Melanocytes & Colonic epithelium \\
\hline Mesothelium & Pancreatic centroacinar cells \\
\hline Neurons (cerebellum) & Pancreatic ducts, interacinar \\
\hline Neurons (cerebrum) & Rectal epithelium \\
\hline Ovarian stroma & Small intestinal epithelium \\
\hline \multicolumn{2}{|l|}{ Ovary, corpus luteum } \\
\hline \multicolumn{2}{|l|}{$\begin{array}{l}\text { Ovary, primary follicle and germ } \\
\text { cells }\end{array}$} \\
\hline \multicolumn{2}{|l|}{ Pancreatic acinar cells } \\
\hline \multicolumn{2}{|l|}{ Pancreatic islets } \\
\hline Parathyroid & \\
\hline
\end{tabular}

\section{RNA Gene Expression Profiling}

Gene expression profiles of a subset of tumor cases were obtained on U95a GeneChips (Affymetrix, Santa Clara, CA), as reported previously (6).

\section{RESULTS}

The degree of Cdx2 protein expression, as determined by immunohistochemistry, was compared with the level of $C d x 2$ RNA transcript levels for a subset of tumors. Transcript levels determined by hybridization to GeneChip oligonucleotide arrays (Affymetrix Inc.) were available for 20 breast adenocarcinomas, 19 colon adenocarcinomas, 2 gastric adenocarcinomas, 12 lung adenocarcinomas, 12 


\begin{tabular}{|c|c|c|c|c|c|}
\hline Staining Pattern & 0 & $1+$ & $2+$ & $3+$ & $4+$ \\
\hline Ampullary carcinoma & 2 & 1 & 1 & 1 & 1 \\
\hline Bladder/ureter transitional cell carcinoma & 7 & 0 & 0 & 0 & 0 \\
\hline Breast adenocarcinoma & 70 & 0 & 0 & 0 & 0 \\
\hline \multicolumn{6}{|l|}{ Carcinoid tumors } \\
\hline Lung & 5 & 2 & 0 & 0 & 0 \\
\hline Common bile duct & 1 & 1 & 0 & 0 & 0 \\
\hline Foregut (stomach) & 3 & 0 & 0 & 0 & 0 \\
\hline Midgut (ileum \& appendix) & 0 & 0 & 1 & 1 & 7 \\
\hline Hindgut (rectum) & 2 & 2 & 1 & 3 & 1 \\
\hline Cholangiocarcinoma & 8 & 7 & 2 & 0 & 0 \\
\hline Colorectal adenocarcinoma & 0 & 4 & 2 & 5 & 49 \\
\hline Gallbladder adenocarcinoma & 4 & 2 & 0 & 0 & 0 \\
\hline Gastroesophageal adenocarcinoma & 88 & 23 & 20 & 15 & 18 \\
\hline \multicolumn{6}{|l|}{ Germ cell tumors } \\
\hline Dysgerminoma & 3 & 1 & 0 & 0 & 0 \\
\hline Embryonal Carcinoma & 3 & 0 & 0 & 0 & 0 \\
\hline Seminoma & 6 & 0 & 0 & 0 & 0 \\
\hline Yolk sac tumor & 1 & 1 & 2 & 1 & 0 \\
\hline Hepatocellular carcinoma & 12 & 0 & 0 & 0 & 0 \\
\hline \multicolumn{6}{|l|}{ Lung carcinoma } \\
\hline Adenocarcinoma & 33 & 1 & 1 & 0 & 0 \\
\hline Large cell undifferentiated carcinoma & 1 & 0 & 0 & 0 & 0 \\
\hline Small cell/Neuroendocrine carcinoma & 2 & 0 & 0 & 0 & 0 \\
\hline Squamous cell carcinoma & 13 & 0 & 0 & 0 & 0 \\
\hline Melanoma & 1 & 0 & 0 & 0 & 0 \\
\hline Mesothelioma & 28 & 0 & 0 & 0 & 0 \\
\hline \multicolumn{6}{|l|}{ Ovarian tumors } \\
\hline Clear cell ca & 1 & 1 & 0 & 0 & 0 \\
\hline Endometrioid adenocarcinoma & 7 & 1 & 0 & 1 & 1 \\
\hline Granulosa cell tumor & 8 & 0 & 0 & 0 & 0 \\
\hline Mucinous adenocarcinoma & 4 & 0 & 0 & 1 & 0 \\
\hline Serous papillary carcinoma & 39 & 1 & 1 & 0 & 0 \\
\hline Undifferentiated carcinoma & 7 & 0 & 0 & 0 & 0 \\
\hline \multicolumn{6}{|l|}{ Pancreatic tumors } \\
\hline Ductal (typical) adenocarcinoma & 16 & 8 & 0 & 0 & 0 \\
\hline Mucinous adenocarcinoma & 0 & 0 & 0 & 0 & 1 \\
\hline Acinar cell carcinoma & 2 & 0 & 0 & 0 & 0 \\
\hline Islet cell tumor & 10 & 2 & 1 & 0 & 1 \\
\hline Prostate adenocarcinoma & 100 & 1 & 0 & 1 & 0 \\
\hline Renal cell carcinoma & 35 & 0 & 0 & 0 & 0 \\
\hline \multicolumn{6}{|l|}{ Salivary gland tumors } \\
\hline Acinic cell carcinoma & 4 & 0 & 0 & 0 & 0 \\
\hline Adenoid cystic carcinoma & 17 & 0 & 0 & 0 & 0 \\
\hline Polymorphous low grade adenocarcinoma & 3 & 0 & 0 & 0 & 0 \\
\hline Salivary duct carcinoma & 3 & 0 & 0 & 0 & 0 \\
\hline Sarcomatoid carcinoma (various sites) & 14 & 0 & 0 & 0 & 0 \\
\hline \multicolumn{6}{|l|}{ Thyroid tumors } \\
\hline Follicular carcinoma & 9 & 0 & 0 & 0 & 0 \\
\hline Papillary carcinoma & 12 & 0 & 0 & 0 & 0 \\
\hline Uterus (Endometrioid carcinoma) & 18 & 3 & 1 & 1 & 0 \\
\hline
\end{tabular}

lung squamous carcinomas, 10 renal carcinomas, 8 hepatocellular carcinomas, 14 ovarian carcinomas, and 30 prostate adenocarcinomas. For comparison to the semiquantitative immunohistochemical scoring, the hybridization intensity of $C d x 2$ on the GeneChips, which represents the range of RNA transcript levels, was scaled into quartiles. In general, there was good agreement between the average immunohistochemical score and the average transcript score for the subgroups of cancers (Fig. $1)$.

Table 1 shows the immunohistochemical results for the panel of normal tissues examined. Strong, diffuse Cdx2 staining was seen in intestinal epithelium, including tissue from the duodenum, ileum, appendix, colon, and rectum. The epithelium of major pancreatic ducts showed focal patchy staining, whereas centroacinar cells and the epithelium of pancreatic interacinar ductules and small pancreatic ducts showed strong diffuse staining. Pancreatic acinar epithelium and islet cells did not stain for Cdx2. No other normal tissue types had detectable Cdx2 staining. Figure 2 shows examples of Cdx2 immunohistochemistry in pancreas and other normal tissues.

Table 2 contains the results of Cdx2 immunohistochemical findings for the complete set of tumors examined. Extensive nuclear staining ( $>50 \%$ of cells) for Cdx2 was most commonly seen in colorectal adenocarcinomas (54 of 60 , 90\%; Figs. 3-4). Other adenocarcinomas with extensive nuclear Cdx2 staining included gastroesophageal adenocarcinomas (33 of 164, 
Cdx2 expression in carcinomas

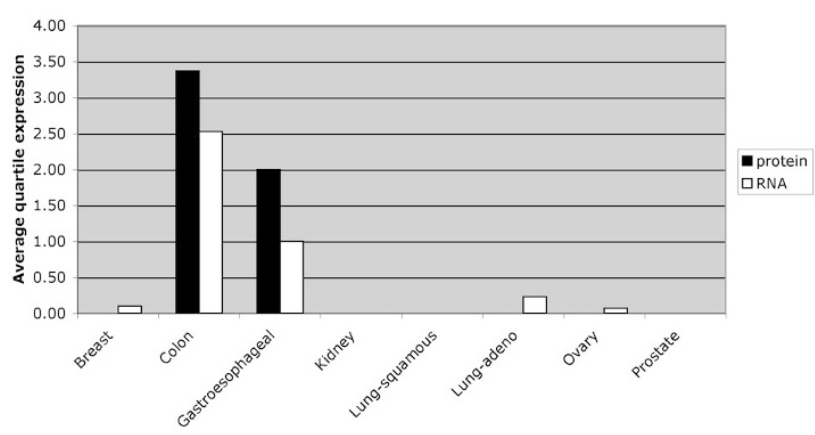

FIGURE 1. Comparison of Cdx2 RNA and protein expression in carcinomas. The scaled hybridization intensity values obtained from oligonucleotide microarray analysis of RNA transcripts present in tumor samples were translated into quartiles and assigned values of $1,2,3$, or 4 (from lowest to highest fluorescence intensity), with a zero value indicating no fluorescence above background. The staining pattern of Cdx2 immunohistochemistry obtained from histologic sections of the same tumors were also separated into 5 groups ( 0 through 4 , see Materials \& Methods section). The mean score for each cancer type is shown, with protein levels represented by filled bars and RNA levels represented by open bars. There is good correlation between the results of RNA and protein expression detected by these methods, with both methods showing colorectal adenocarcinomas with the highest level of expression, followed by gastroesophageal adenocarcinomas.

$20 \%$ ), ovarian endometrioid adenocarcinomas ( 2 of $10,20 \%$ ) and mucinous adenocarcinomas (1 of 5 , $20 \%$ ), uterine endometrioid adenocarcinoma ( 1 of 23 , $4.3 \%$ ), and prostatic adenocarcinoma (1 of $102,1 \%$ ). Although no typical ductal pancreatic adenocarcinoma showed Cdx2 staining, the single case of mucinous pancreatic adenocarcinoma showed strong diffuse immunoreactivity.

Neuroendocrine tumors in general exhibited a pattern of Cdx2 staining that mirrored the anatomic distribution of Cdx2 expression in nonneuroendocrine carcinomas. Eight of 9 (89\%) midgut and 4 of 9 (44\%) hindgut carcinoids showed extensive Cdx2 expression, with carcinoids of the stomach, biliary tract, and lung showing no or only focal Cdx2 expression. The majority of pancreatic islet cell tumors also showed no or little staining for Cdx2, with only 1 of 14 cases (7.1\%) showing $>50 \%$ of cells staining.

\section{DISCUSSION}

$C d x 2$ is a gene essential for normal mammalian development. In adult animals, including humans, it is expressed in intestinal epithelial cells, where it acts as a transcription factor. Genes that are regulated by $C d x 2$, such as sucrase-isomaltase and lactase, are associated with the mature enterocyte phenotype, and the current paradigm is that $C d x 2$ is a master "control gene" for intestinal epithelial differentiation. Our data support the use of Cdx2 immunohistochemistry as a marker of intestinal cellular differentiation, even in the malignant state.
The highest frequency of extensive Cdx2 expression was seen in colorectal adenocarcinomas (90\%). Ampullary and gastroesophageal adenocarcinomas, which often have histologic and histochemical evidence of intestinal differentiation, also had a substantial percentage of tumors with extensive Cdx2 expression (33 and 20\%, respectively). Neuroendocrine tumors arising from various epithelia exhibit Cdx2 expression that mirrors that seen in the native non-neuroendocrine epithelia, with the highest frequency of extensive Cdx2 expression in the midgut (89\%) and hindgut (44\%). Interestingly, Cdx2 expression has been reported to be lower in the distal colorectum than in the rest of the gastrointestinal tract during development (2), and the hindgut carcinoids in our collection were exclusively from the rectum. It is possible that the lower frequency of rectal carcinoids highly expressing Cdx2, when compared with the frequency of midgut carcinoids, is a reflection of this relative biological difference seen in the cell populations from which these tumors originate. The finding of high Cdx2 levels in neuroendocrine tumors derived from intestinal epithelium suggests that Cdx2 may also be playing a role in normal neuroendocrine cell differentiation, or that Cdx2 expression in gut epithelium does not alone determine differentiation to the absorptive cell phenotype.

When the $C d x 2$ gene is eliminated by one copy in mice, the animals develop hamartomatous polyps, in which it has been shown that the wild-type $C d x 2$ allele is not expressed. This observation has led to the screening of patients with intestinal hamartomatous polyposis syndromes for germline inactivating mutations of $C d x 2$; however, no such mutations have been identified (10). In cell culture experiments, induced expression of $C d x 2$ has been shown to arrest proliferation in undifferentiated intestinal cells (3). This observation, along with the heterozygous mouse model, suggests that $C d x 2$ may act as a tumor suppressor. However, in surveys of human colon carcinoma, except for a few rare tumors that also expressed high microsatellite instability (MI), gene mutation has not been found $(10-12)$. Because $C d x 2$ is neither mutated, nor is its gene expression lost in most cases of colorectal adenocarcinomas, it seems highly unlikely that it plays a role as a significant tumor suppressor. A subset of colon cancers described as "large cell minimally differentiated carcinomas" has been reported as lacking expression of $C d x 2$ (8). These tumors also had a high incidence of MI, suggesting that both MI and Cdx2 loss are molecular alterations in colon cancer manifested by this large cell morphology. Because Cdx2 mutations occur in areas of repetitive DNA sequence within the gene (11), it is likely that Cdx2 is not selected as a tumor suppressor gene when it is mutated in these can- 

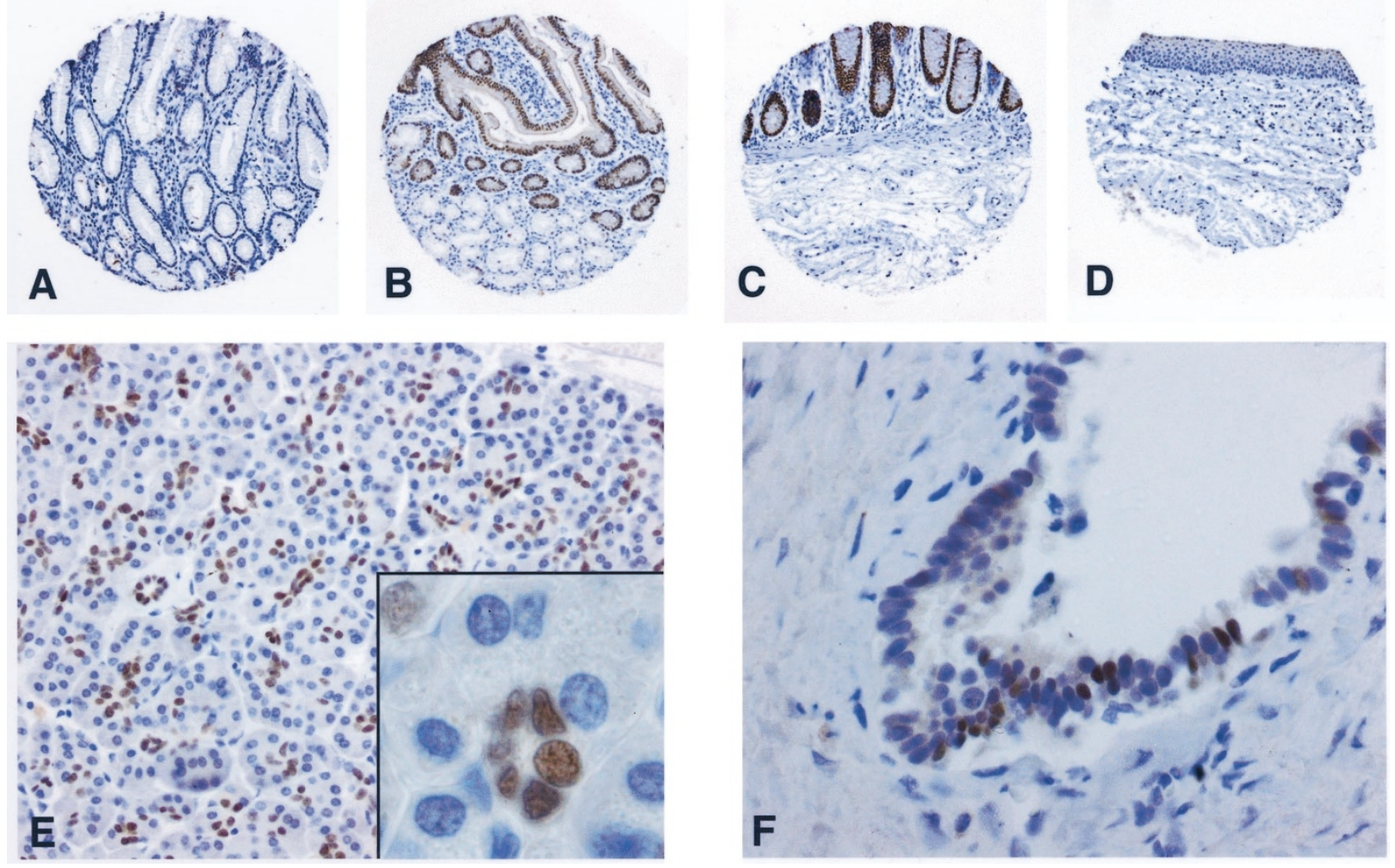

FIGURE 2. Examples of Cdx2 immunohistochemistry in non-neoplastic tissue. A, gastric antrum sample in tissue microarray showing no nuclear staining (original magnification, $100 \times$ ). B, duodenum sample in tissue microarray showing staining exclusively in enterocytes. Note that Brunner gland epithelium exhibits no staining (original magnification, $100 \times$ ). C, colon sample in tissue microarray showing staining exclusively in colonocytes (original magnification, $100 \times$ ). D, anus sample in tissue microarray showing no nuclear staining (original magnification, $200 \times$ ). E, standard section of pancreas showing staining of centroacinar cells and small ducts (original magnification, $200 \times$ ). The inset shows a higher power of an acinus (original magnification, $1000 \times$ ). F, large pancreatic duct showing spotty epithelial staining (original magnification, 400×).

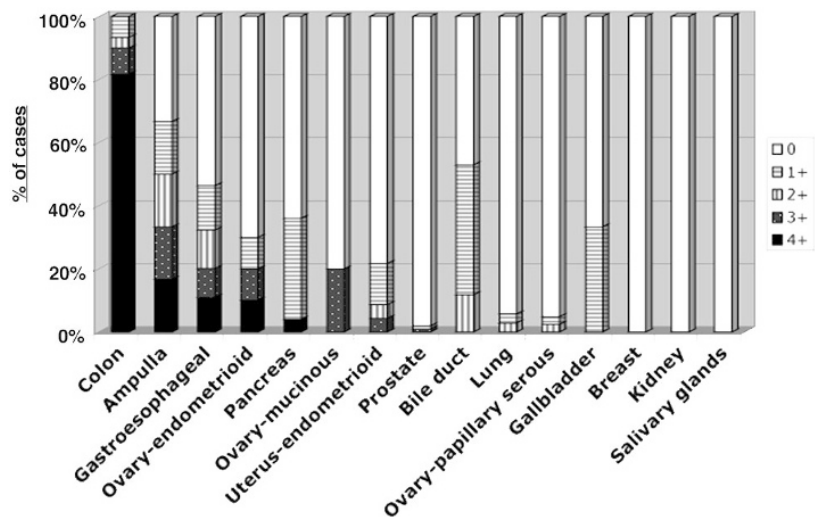

FIGURE 3. Results of Cdx2 immunohistochemistry in adenocarcinomas. Immunohistochemical staining was graded $0-4+$ based on the percent of cells showing nuclear staining for Cdx2. Colorectal adenocarcinomas had the greatest percentage of cases showing strong diffuse Cdx2 staining (3-4+), followed distantly by ovarian, ampullary, and gastroesophageal adenocarcinomas.

cers but may be mutated as an "innocent bystander" as a consequence of the DNA mutator phenotype associated with MI. Once inactivated, however, it is also likely that the undifferentiated large cell phenotype is a consequence of $C d \times 2 \mathrm{mu}-$ tation. This hypothesis is supported by studies with the IEC-6 cell line, a human colon cancer cell line that grows as undifferentiated tumors in nude mice. When Cdx2 expression is induced in these cells, the cells form tumors with glandular and villous structure, and ultrastructural features of both enterocytes and goblet cells are found (3).

The data presented in this study show that strong, extensive nuclear Cdx2 immunohistochemical staining is very common in colorectal adenocarcinomas, with smaller numbers of adenocarcinomas of the stomach, esophagus, pancreas, ovary, and uterus showing this pattern. Of particular note is the differential expression of $\mathrm{Cdx} 2$ protein in mucinous tumors of the ovary as compared with adenocarcinomas arising in the colorectum. There often exists some uncertainty as to the primary site of origin of carcinomas in the ovary that show glandular or mucinous differentiation. The ovarian tumors used in this series were carefully screened to include only those cases with an adequate clinical examination to exclude a gastrointestinal primary tumor. Although not completely specific, the relatively low numbers of mucinous ovarian tumors showing extensive Cdx2 expression may make this a useful marker, perhaps as part of a panel of immunohistochemical stains, in separating metastatic gastrointestinal tumors from primary mucinous 

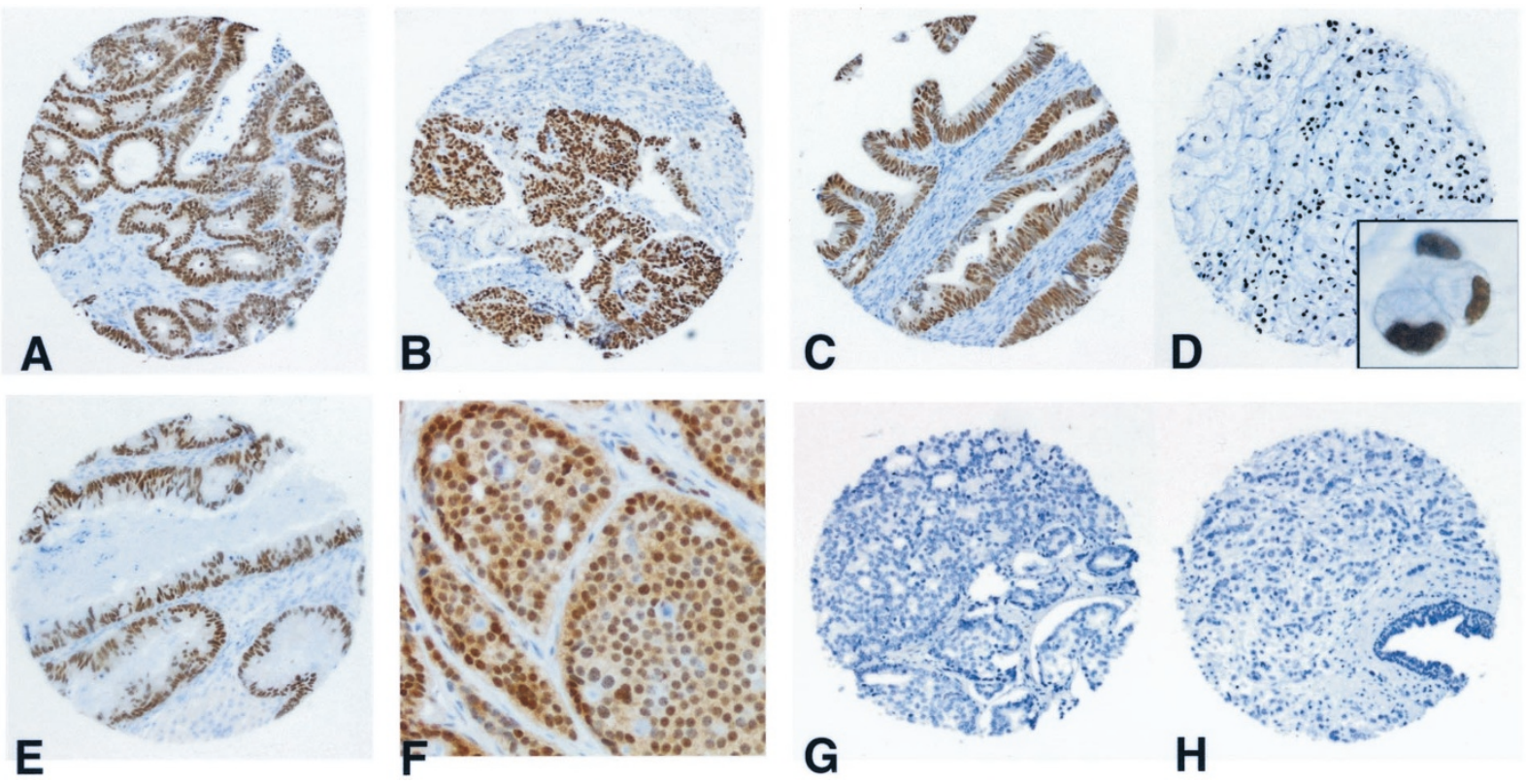

FIGURE 4. Examples of Cdx2 immunohistochemistry in cancers. A, colon adenocarcinoma, well differentiated, showing diffuse nuclear staining. B, colon adenocarcinoma, poorly differentiated, showing diffuse nuclear staining. C, gastric adenocarcinoma, intestinal type, well differentiated, showing diffuse nuclear staining. D, gastric adenocarcinoma, signet ring cell type, showing diffuse nuclear staining. E, ovarian carcinoma, mucinous subtype, showing diffuse nuclear staining. F, carcinoid tumor of ileum, showing diffuse nuclear staining. G, prostate adenocarcinoma, negative for staining. $\mathbf{H}$, breast adenocarcinoma, negative for staining. Panels A-E, G, and $\mathbf{H}$ are of samples from tissue microarrays (original magnification, $100 \times$; inset in Panel D is $1000 \times$ original magnification), and Panel F is from a standard histologic section ( $200 \times$ original magnification).

ovarian carcinomas. More definitive proof of the usefulness of this marker for this purpose will require a more focused study, with a larger number of cases.

Other potential uses of this marker include the workup of metastatic tumors at other sites. The marker may aid in the differential diagnosis of welldifferentiated neuroendocrine tumors first detected in the liver. Extensive positive Cdx2 staining predicts a metastasis from a gastrointestinal carcinoid of midgut or hindgut origin. Negative or focal Cdx2 staining predicts a source from the lung, stomach, biliary tract, or pancreas. As has been reported in abstract form by another group (13), our results suggest that Cdx2 immunohistochemistry is also useful in distinguishing primary lung adenocarcinomas from gastrointestinal metastases.

In conclusion, our immunohistochemical survey of Cdx2 protein expression is in excellent agreement with the results of global gene expression studies in which oligonucleotide microarrays were used. It is expected that the "mining" of such global gene expression surveys of human cancers will yield other candidate protein markers that can be assayed by immunohistochemistry to provide useful clinicopathologic information.

Note added in proof: During the review period of this manuscript, two studies were published (Barbareschi M et al. Am J Surg Pathol 2003;27:141-9; Werling RW et al. Am J Surg Pathol 2003;27:303-10) that similarly examined the range of Cdx2 expres- sion in normal human tissues and cancers. The portions of these studies that overlap with our data are in good agreement with the distribution of Cdx2 expression we report here.

Acknowledgment: We thank Sharon Birdsall for assistance with histologic and immunohistochemical techniques.

\section{REFERENCES}

1. James R, Erler T, Kazenwadel J. Structure of the murine homeobox gene cdx-2. Expression in embryonic and adult intestinal epithelium. J Biol Chem 1994;269:15229-37.

2. Silberg DG, Swain GP, Suh ER, Traber PG. Cdx1 and cdx2 expression during intestinal development. Gastroenterology 2000;119:961-71.

3. Suh E, Traber PG. An intestine-specific homeobox gene regulates proliferation and differentiation. Mol Cell Biol 1996; 16:619-25.

4. Drummond FJ, Sowden J, Morrison K, Edwards YH. Colon carbonic anhydrase 1: transactivation of gene expression by the homeodomain protein Cdx2. FEBS Lett 1998;423:218-22.

5. Giordano TJ, Shedden KA, Schwartz DR, Kuick R, Taylor JM, Lee N, et al. Organ-specific molecular classification of primary lung, colon, and ovarian adenocarcinomas using gene expression profiles. Am J Pathol 2001;159:1231-8.

6. Su AI, Welsh JB, Sapinoso LM, Kern SG, Dimitrov P, Lapp H, et al. Molecular classification of human carcinomas by use of gene expression signatures. Cancer Res 2001;61:7388-93.

7. Qualtrough D, Hinoi T, Fearon E, Paraskeva C. Expression of CDX2 in normal and neoplastic human colon tissue and during differentiation of an in vitro model system. Gut 2002; 51:184-90. 
8. Hinoi T, Tani M, Lucas PC, Caca K, Dunn RL, Macri E, et al. Loss of CDX2 expression and microsatellite instability are prominent features of large cell minimally differentiated carcinomas of the colon. Am J Pathol 2001;159:2239-48.

9. Bai YQ, Yamamoto H, Akiyama Y, Tanaka H, Takizawa T, Koike M, et al. Ectopic expression of homeodomain protein CDX2 in intestinal metaplasia and carcinomas of the stomach. Cancer Lett 2002;176:47-55.

10. Woodford-Richens KL, Halford S, Rowan A, Bevan S, Aaltonen LA, Wasan $\mathrm{H}$, et al. CDX2 mutations do not account for juvenile polyposis or Peutz-Jeghers syndrome and occur infrequently in sporadic colorectal cancers. Br J Cancer 2001;84:1314-6.
11. Wicking C, Simms LA, Evans T, Walsh M, Chawengsaksophak K, Beck F, et al. CDX2, a human homologue of Drosophila caudal, is mutated in both alleles in a replication error positive colorectal cancer. Oncogene 1998;17: 657-9.

12. Yagi OK, Akiyama Y, Yuasa Y. Genomic structure and alterations of homeobox gene CDX2 in colorectal carcinomas. Br J Cancer 1999;79:440-4.

13. Murer B, Chilosi M, Barbareschi M, Macri E, Loda M, Doglioni C. Primary vs. metastatic pulmonary adenocarcinoma: Cdx-2 is a specific and sensitive marker of tumors of colonic origin [abstract]. Mod Pathol 2002;15:325A-6A.

\section{Book Review}

\section{MacLennan GT, Resnick, MI, Bostwick DG: Pa- thology for Urologists, 207 pp, Philadel- phia, WB Saunders, 2002 (\$160.00).}

In this book prepared for urologists, Drs. MacLennan, Resnick, and Bostwick have systematically reviewed the major organ systems and the major pathological conditions that affect those organ systems. The chapters are organized by the organ system and include kidney, bladder (urethra, renal pelvis, and ureter), prostate, testis, spermatic cord, penis and scrotum, and adrenal. Each chapter reviews the normal histology (a feature often lacking from general urologic textbooks) followed by pathological conditions. Each entity is briefly described from a clinical standpoint and then correlated with the gross and histological findings. These are then accompanied by several photographs or photomicrographs of the condition with captions pointing out salient features. In addition, congenital dis- orders of the organ systems are covered where appropriate.

The advantage of this textbook is that it is geared toward urologists rather than pathologists. In particular, this textbook would be an excellent study tool for resident physicians in urology preparing to take their board examinations. Many of the salient features pointed out in the photographs are "classic" board examination questions. This book is also a valuable tool for the practicing urologist, as its organization by organ system makes it a quick and easy reference. As the authors mention in their preface, some very rare entities may be missing from the textbook, but the vast majority of uropathologic conditions are covered in this beautifully illustrated, well-organized textbook.

\section{Jeffrey Holzbeierlein \\ University of Kansas School of Medicine \\ Kansas City, Kansas}

